\title{
Multi-objective Optimization to Increase Nusselt Number and Reduce Friction Coefficient of Water/Carbon Nanotubes via NSGA II using Response Surface Methodology
}

\author{
Amin Moslemi Petrudi, Pourya Fathi, Masoud Rahmani \\ Department of Mechanical Engineering, Tehran University, Iran
}

* Corresponding author email: amin.moslemi2020@gmail.com

Received: 31 January 2020 / Accepted: 04 March 2020 / Published: 05 March 2020

\begin{abstract}
Heat transfer science is one of the most important and most applied engineering sciences, with the importance of energy management and energy conservation being doubled. Because of their properties, nanofluids have been widely used in various industries, making them particularly important to study. In this paper, the Nusselt number and coefficient of friction with volume fraction ranging from 0 to 0.1 at approximately Reynolds numbers of 200 to 5000 are studied experimentally. Higher thermal conductivity, better stability, lower pressure drop was observed using nanoparticles of solid particles. NSGA II algorithm was used to maximize Nusselt number and minimum friction coefficient by changing temperature and volume fraction of nanoparticles. To obtain Nusselt number and friction coefficient based on the temperature and volume fraction of the nanoparticles, the experimental data response surface methodology was used and with increasing Reynolds number, the Nusselt number increased and the friction coefficient decreased. In order to evaluate the objective functions in the optimization, the response surface methodology is attached to the optimization algorithm. At the end, the Pareto Front and its corresponding optimal points are presented.
\end{abstract}

Keywords: Nusselt number; Multi-objective optimization; Nanofluids; Friction coefficient; Pareto front.

\section{Introduction}

Due to the rapid development of nanotechnology, nanometer-sized solid particles (between 1 and $100 \mathrm{~nm}$ ) were replaced with micrometer-sized particles in the fluid, which was called nanofluid. Higher thermal conductivity, better stability, and lower pressure drop were observed using nanoparticles of solid particles. Numerous studies have been performed on heat transfer and pressure drop of nanofluid [1]. Nanofluids have been rapidly attracted to various industries because of their unique thermal conductivity. Art optimization is about finding the best answer in the current situation. Optimization is used to design and maintain engineering, economic and even social systems in order to minimize cost and or maximize profits [2]. Optimization methods have been used to increase productivity and reduce costs. The structure and principles of multi-objective optimization are the same as single-objective optimization, but in some ways the number of variables and objective functions in these methods are increased and are used to find a set of optimal answers rather than an optimal one. It is valuable to reduce energy consumption and increase productivity [3]. TiO2/SiO2 nanofluids as novel inhibitors for the stability of asphaltene particles in crude oil: Mechanistic understanding, screening, modeling, and optimization. [4]. Thermal Conductivity of Suspensions Containing Nanosized SiC Particles [5]. Design of microchannel heat sink with wavy channel and its time-efficient optimization with combined RSM and FVM methods [6]. Numerical and experimental studies on laminar hydrodynamic and thermal characteristics in fractal-like microchannel networks. Part A: Comparisons of two numerical analysis methods on friction factor and Nusselt number [7]. Impacts of nanofluid flow on skin friction factor and Nusselt number in curved tubes with constant mass flow [8]. Experiment and Artificial Neural Network Prediction of Thermal Conductivity and Viscosity for Alumina-

Copyright (C) 2020. The Author(s). Published by AIJR Publisher.

This is an open access article under Creative Commons Attribution-NonCommercial 4.0 International (CC BY-NC 4.0) license, which permits any non-commercial use, distribution, adaptation, and reproduction in any medium, as long as the original work is 
Water Nanofluids [9]. Numerical simulation and sensitivity analysis of effective parameters on heat transfer and homogeneity of Al2O3 nanofluid in a channel using DPM and RSM [10]. Evaluation of viscosity and thermal conductivity of graphene nanoplatelets nanofluids through a combined experimental-statistical approach using respond surface methodology method [11]. The overall aims of nanofluid research and development are to exploit the unique properties of nanoparticles. In this way, the transfer properties and heat transfer performance of nanofluids can be classified and the nanofluid technology expanded to enhance the thermal properties of other conventional fluids [12]. The main reasons for the increase in heat transfer of nanofluids generally depend on the following factors:

- $\quad$ Particle surface area increase (Surface to volume ratio in particles)

- The interaction between nanoparticles and fluid molecules

- Increased perturbations due to mixing of particles and fluid

Despite numerous efforts, the mechanisms involved in enhancing heat transfer in nanofluids remain unknown [13]. Therefore, efforts are still being made to develop nanofluids in which different nanoparticles with different dimensions are used. Meanwhile, water nanoparticles/aluminum oxide and water/copper oxide are widely used by researchers [14]. The past decade has witnessed numerous research activities in the field of nanofluids and their thermal performance. Most of these studies are devoted to the determination of thermal indices such as effective thermal conductivity under static conditions, heat transfer coefficient and heat transfer coefficient with phase change [15]. more research in the field of nanofluid by increasing particle mobility leads to a new science in relation to thermal conductivity. many of the experimental studies that have been done to determine the effective thermal conductivity coefficient in nanofluid show that a model that can accurately predict thermal conductivity of suspension solutions is not presented [16]. nanofluids were used in the present paper to maximize the Nusselt number and the minimum friction coefficient with variation at temperatures (200 to 5000) and volume fraction (0 to 1.0) nanofluid. in order to obtain the friction coefficient and the Nusselt number in terms of temperature and volume fraction, the response surface method is used. the model is modeled using the response surface method and the results are explained as the objective function of the algorithm.

\section{Nanofluid Properties}

The thermophysical properties of fluid are modified by adding nanoparticles to the base fluid. They include the density, viscosity, thermal conductivity coefficient, and special heat. Various researchers have expressed a different view of the effect of adding nanoparticles on the values of these properties [17]. in general, the addition of nanoparticles causes an increase in these properties besides the special heat, which decreases with the addition of nanoparticles. the percentage of this increase depends on different factors, including percentage of volume of nanoparticles, nanoparticles properties, basic fluid properties and temperature. due to these researches, nanofluids have found many applications that have caused the investigation of these properties to be of particular importance. due to the concentration of nanoparticles in the base fluid, the properties of nanofluid are adjustable by changing the nanoparticles concentration.

\section{Nusselt}

The Nusselt number is a dimensionless number expressed in heat transfer expressing the heat transfer transmitted through convection (or movement) to the heat transmitted through conduction (or guidance) on the system boundary. This number denoted by symbol $(\mathrm{Nu})[18]$.

\section{Coefficient of Friction}

Coefficient of friction is the ratio of the vertical force sector to the force of friction. According to Coulomb's theory, the coefficient of friction of each material is constant. however, the experiments show that the coefficient of friction depends on factors such as contact pressure, slip speed, temperature, number of load cycles, etc. 


\section{Genetic Algorithm}

This algorithm is based on Darwin's evolutionary theory. Darwin's evolutionary theory is based on the evolution of generations, stating that over time a group of particular beings will remain those who are more qualified to live and are better than their counterparts, and that other individuals in that group will be eliminated and their offspring will be destroyed. He went. In this algorithm, a code is assigned to each individual (problem answer) containing the genes (attributes) of the answer. After defining the answers and forming the first generation, subsequent generations are formed according to the integration of the parents (the initial population). The algorithm is also used to prevent the algorithm from stopping the local optimization of the mutation operator, in which each mutant will mutate alone and will be passed on to the next generation [19].

\section{NSGA II Method}

The optimization method is used to solve the optimization problems where the salient points of this optimization method are:

- effectiveness of this method is retained in non - convex problems.

- with the help of this method, optimum quasi - optimal responses are determined.

- The second version of the NSGA algorithm, called NSGA II, was introduced due to the relatively high sensitivity that the algorithm responds to shared and fitness parameters and other parameters. The main features of this algorithm are:

- Definition of the compressive distance as an alternative property for ways like sharing for life

- Using the two binary tournament choice operator

Save and archive the answers which have been obtained in previous steps of the algorithm.

Answers $i-1$ and $i-2$ the answers before and after are the answer of $\mathrm{i}$, then the distance of the congestion of my answer is as follows and Figure 1 shows Crowding distance in NSGA-II.

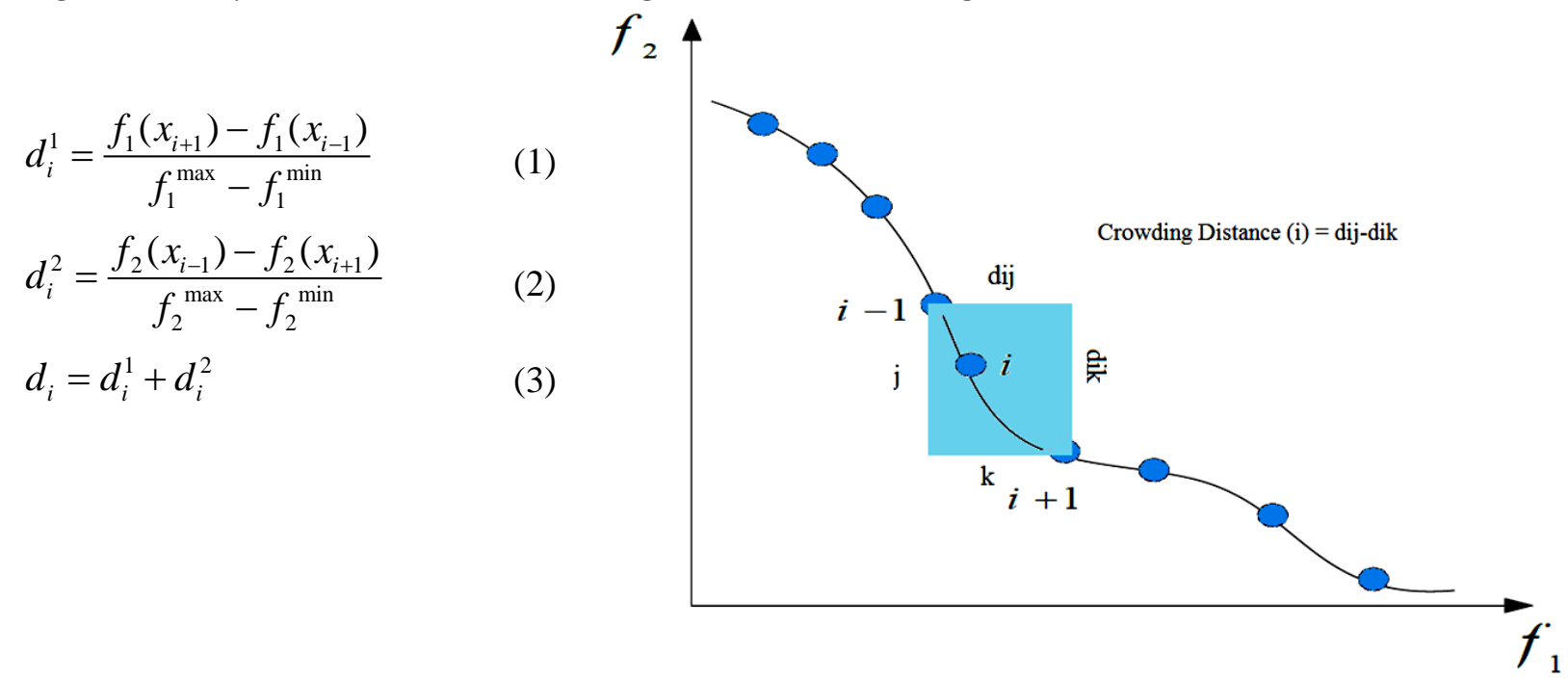

Figure 1: Crowding distance in NSGA-II.

Therefore, in a binary tournament, the answer $\mathrm{i}$ is superior to the answer $\mathrm{j}$ if either of the following conditions is true:

- Rank $i$ is less than rank $j(r i<r j)$.

- If answer $i$ is equal to $j$ then answer $i$ is superior to answer $j$ if the answer distance $i$ is greater than the answer distance $j(\mathrm{dj}>\mathrm{dj})$.

After the rank and process of a new population, a new population of alternatives is established and then using the common methods used in genetic algorithms, new alternatives are produced and then the earlier stages are repeated. at the beginning of iteration $t$, a population of children $(\mathrm{Qt})$ is produced by conventional 
methods of genetic algorithm and then the total population of parents and children $(\mathrm{Rt}=\mathrm{pt} \mathrm{Qt})$ is regular and divided into different levels. The number of members of the combined population is $2 \mathrm{~N}$, where $\mathrm{N}$ is the number of members of the original population selected by the planner. Among the Rt population, the priority order of $\mathrm{N}$ is the top option and will be sent to the iteration $t+1$. This process is repeated until it reaches the final bet. According to the method used for the formation of the new population, it is clear that this method is sent to repeat the correct answers before switching to the next iteration. The termination condition can be defined in different ways, including the determination of the maximum number of iterations, or not to improve the answers or not to increase the quasi - optimal responses [20]. Figure 2 shows the structure of NSGA-II.

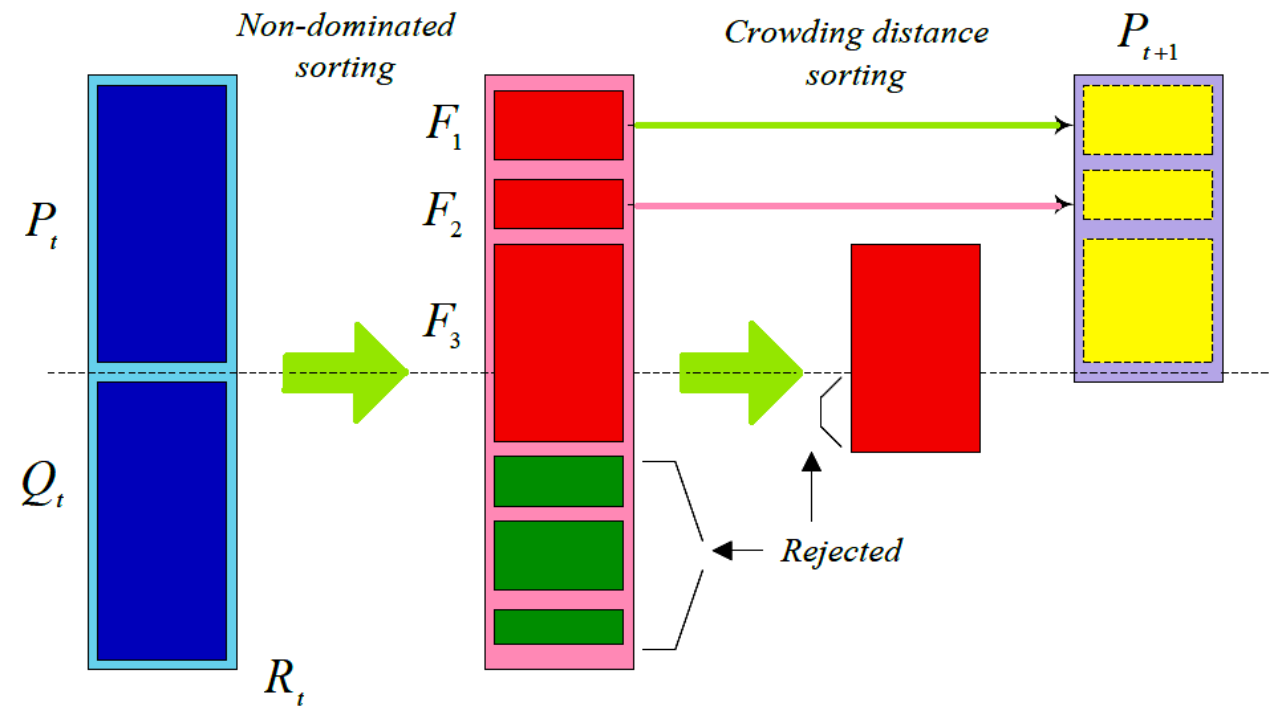

Figure 2: The structure of NSGA-II.

In Figure 2 the flowchart of Algorithm II is presented. after determining the optimal responses, relations between objective functions are determined. In this case, the decision - maker can choose the best answer according to these relationships, their requirements, the importance of each objective function and above level information. In engineering issues, there are many objectives and criteria that are not possible to formulate them as objective functions, and these qualitative criteria can be very helpful in choosing the final response and Figure 3 shows Optimization flowchart [21].

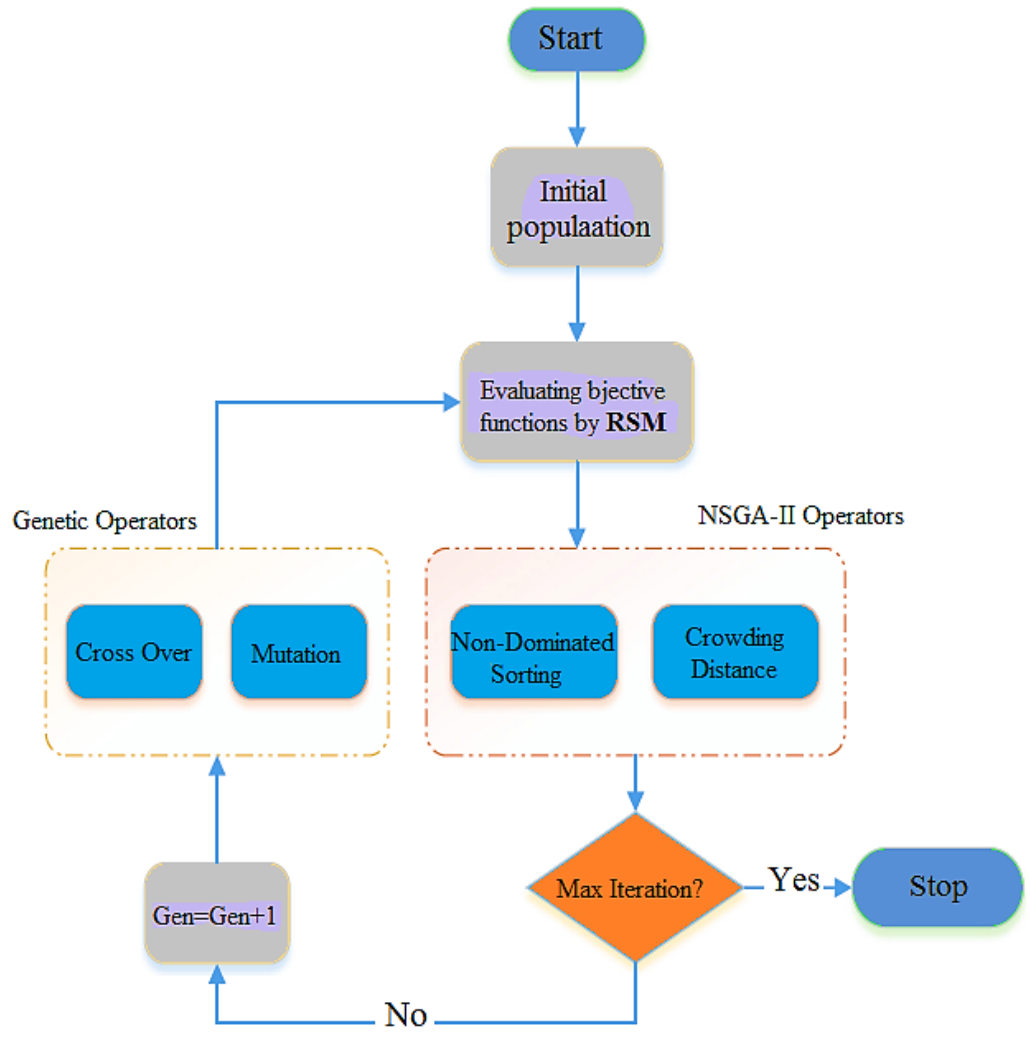

Figure 3: Optimization flowchart. 


\section{Response Surface Methodology}

The response surface methodology is a collection of mathematical and statistical techniques to match the experimental data with polynomial models. the response surface method is presented as one of the experimental modeling methods. the response surface method is one of the approaches in the design of experiments and sciences. In the response surface method, the solution is tried to find a way to estimate the second - order effects and even the local form of the response surface. in this study, specific goals are pursued seriously, which can be used to improve the process by finding optimal inputs, removing the problems and weaknesses of the process and stabilization of it. here, stabilization is an important concept in quality statistics which indicates minimize the effects of secondary variables or friction (friction) [22]. Table 1 shows Analysis of variance (ANOVA) for Friction Smooth Tube 2 factor. Table 2 shows Analysis of variance (ANOVA) for Nusselt Smooth Tube 2. Figure 4 shows Normal probability plot residuals. (a) Friction (b) Nusselt. Figure 5 shows Comparison of the experimental results and predicted values (a) Friction (b) Nusselt. Figure 6 shows Three-dimensional response surface graphs of Friction. Figure 7 shows Three-dimensional response surface graphs of Nusselt. Figure 8 shows Multi-objective optimization results by NSGA-II. Figure 9 shows Pareto optimal front.

\section{Benefits of RSM Method}

- Response Surface Methodology (RSM) method can also receive qualitative variables and be used in analysis and optimization of properties.

- It analyzes and analyzes the interaction between parameters.

- quadratic models can be used to analyze properties and optimization.

- in this method statistical method is determined by interpolation between input variables, optimal values.

Table 1: Analysis of variance (ANOVA) for Friction Smooth Tube 2 factor.

\begin{tabular}{|l|c|c|c|c|c|}
\hline \multicolumn{1}{|c|}{ Source } & Adj SS & Df & Adj MS & F & P \\
\hline Model & 1.72 & 14 & 0.12 & 502.78 & $8.01979 \mathrm{E}-142$ \\
\hline$\varphi$ & $3.196 \mathrm{E}-003$ & 1 & $3.196 \mathrm{E}-003$ & 13.11 & 0.0004 \\
\hline $\mathbf{R e}$ & 0.42 & 1 & 0.42 & 1706.30 & $7.32885 \mathrm{E}-097$ \\
\hline$\varphi \mathbf{R e}$ & $1.611 \mathrm{E}-005$ & 1 & $1.611 \mathrm{E}-005$ & 0.066 & 0.7974 \\
\hline$\varphi^{2}$ & $3.608 \mathrm{E}-003$ & 1 & $3.608 \mathrm{E}-003$ & 14.80 & 0.0002 \\
\hline $\mathbf{R e}^{2}$ & 0.24 & 1 & 0.24 & 964.92 & $2.18677 \mathrm{E}-076$ \\
\hline$\varphi^{2} \mathbf{R}$ & $1.211 \mathrm{E}-005$ & 1 & $1.211 \mathrm{E}-005$ & 0.050 & 0.8239 \\
\hline$\varphi \mathbf{R e}^{2}$ & $1.761 \mathrm{E}-005$ & 1 & $1.761 \mathrm{E}-005$ & 0.072 & 0.7884 \\
\hline$\varphi^{3}$ & $3.492 \mathrm{E}-003$ & 1 & $3.492 \mathrm{E}-003$ & 14.33 & 0.0002 \\
\hline $\mathbf{R e}^{3}$ & 0.15 & 1 & 0.15 & 633.03 & $2.16454 \mathrm{E}-062$ \\
\hline$\varphi^{2} \mathbf{R e}^{2}$ & $8.149 \mathrm{E}-005$ & 1 & $8.149 \mathrm{E}-005$ & 0.33 & 0.5639 \\
\hline$\varphi^{3} \mathbf{R e}^{2}$ & $6.964 \mathrm{E}-006$ & 1 & $6.964 \mathrm{E}-006$ & 0.029 & 0.8660 \\
\hline$\varphi \mathbf{R e}^{3}$ & $5.962 \mathrm{E}-004$ & 1 & $5.962 \mathrm{E}-004$ & 2.45 & 0.1195 \\
\hline$\varphi^{4}$ & $3.462 \mathrm{E}-003$ & 1 & $3.462 \mathrm{E}-003$ & 14.20 & 0.0002 \\
\hline $\mathbf{R e}^{\mathbf{4}}$ & 0.11 & 1 & 0.11 & 457.22 & $1.85369 \mathrm{E}-052$ \\
\hline $\mathbf{R e s i d u a l ~ e r r o r ~}^{\mathbf{2}}$ & 0.046 & 190 & $2.438 \mathrm{E}-004$ & & \\
\hline Total $^{2}$ & 1.76 & 204 & & & \\
\hline
\end{tabular}

Predicted residual error of sum of squares (PRESS) $=0.058$.

$\mathrm{R} 2($ Adequate $)=85.996 \%$ R2 $($ Predicted $)=0.9670 \%$ R2 $($ Adjusted $)=0.9718 \%$. 
Table 2: Analysis of variance (ANOVA) for Nusselt Smooth Tube 2.

\begin{tabular}{|c|c|c|c|c|c|}
\hline Source & Adj SS & Df & Adj MS & $\mathbf{F}$ & $\mathbf{P}$ \\
\hline Model & 5924.33 & 14 & 423.17 & 929.82 & 5.24629E-095 \\
\hline$\varphi$ & 4.77 & 1 & 4.77 & 10.48 & 0.0017 \\
\hline $\mathbf{R e}$ & 11.37 & 1 & 11.37 & 24.98 & $2.63283 \mathrm{E}-006$ \\
\hline$\varphi \mathbf{R e}$ & 11.94 & 1 & 11.94 & 26.23 & $1.58321 \mathrm{E}-006$ \\
\hline$\varphi^{2}$ & 7.54 & 1 & 7.54 & 16.58 & $9.6618 \mathrm{E}-005$ \\
\hline $\mathbf{R e}^{2}$ & 37.80 & 1 & 37.80 & 83.06 & $1.2973 \mathrm{E}-014$ \\
\hline$\varphi^{2} \mathbf{R}$ & 27.26 & 1 & 27.26 & 59.90 & $1.06142 \mathrm{E}-011$ \\
\hline$\varphi \mathbf{R e}^{2}$ & 4.49 & 1 & 4.49 & 9.87 & 0.0022 \\
\hline$\varphi^{3}$ & 8.68 & 1 & 8.68 & 19.08 & $3.1952 \mathrm{E}-005$ \\
\hline $\operatorname{Re}^{3}$ & 30.39 & 1 & 30.39 & 66.78 & $1.30645 \mathrm{E}-012$ \\
\hline$\varphi^{2} \mathbf{R e}^{2}$ & 4.58 & 1 & 4.58 & 10.06 & 0.0020 \\
\hline$\varphi^{3} \mathbf{R e}$ & 27.61 & 1 & 27.61 & 60.67 & $8.35927 \mathrm{E}-012$ \\
\hline$\varphi \mathbf{R e}^{3}$ & 0.22 & 1 & 0.22 & 0.49 & 0.4857 \\
\hline$\varphi^{4}$ & 8.82 & 1 & 8.82 & 19.38 & $2.81043 \mathrm{E}-005$ \\
\hline $\operatorname{Re}^{4}$ & 22.53 & 1 & 22.53 & 49.50 & $3.04651 \mathrm{E}-010$ \\
\hline Residual error & 43.23 & 95 & 0.46 & & \\
\hline Total & 5967.56 & 109 & & & \\
\hline
\end{tabular}

Predicted residual error of sum of squares $($ PRESS $)=58.49$.

R2 (Adequate) $=101.790 \%$ R2 (Predicted) $=0.9902 \%$ R2 (Adjusted) $=0.9917 \%$.

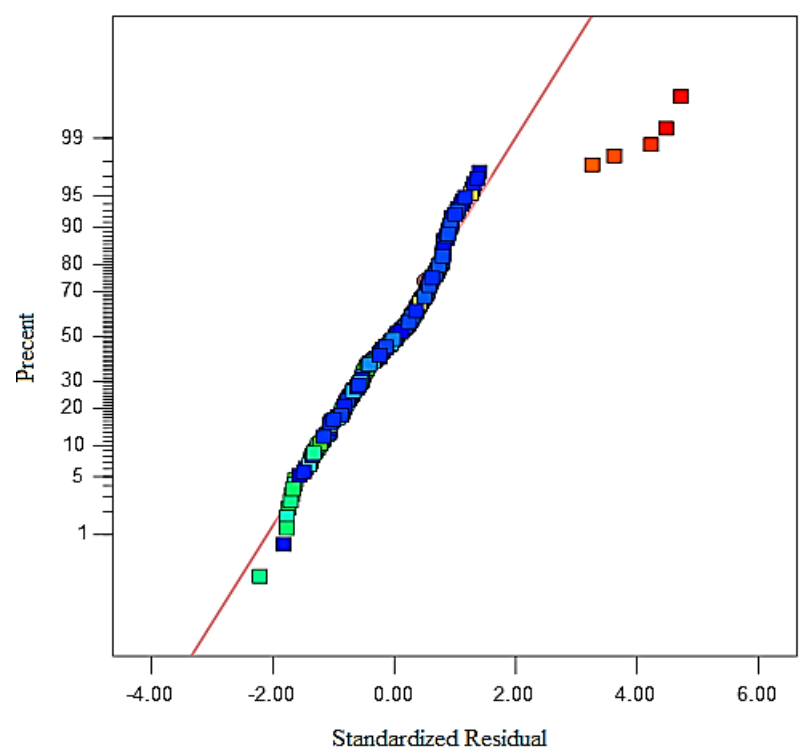

(a)

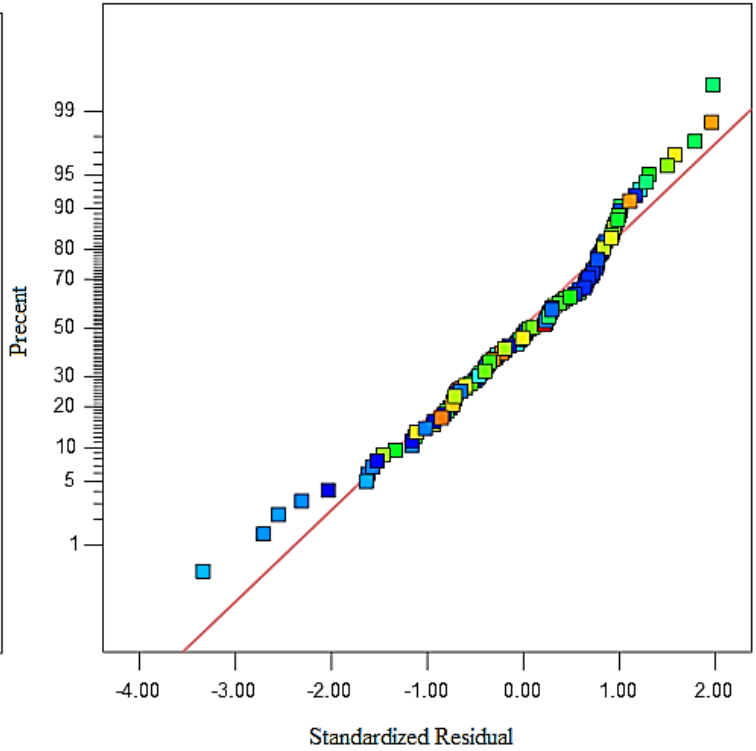

(b)

Figure 4: Normal probability plot residuals. (a) Friction (b) Nusselt. 
Petrudi et al., J. Mod. Sim. Mater.; Vol. 3 Issue 1, pp: 1-14, 2020

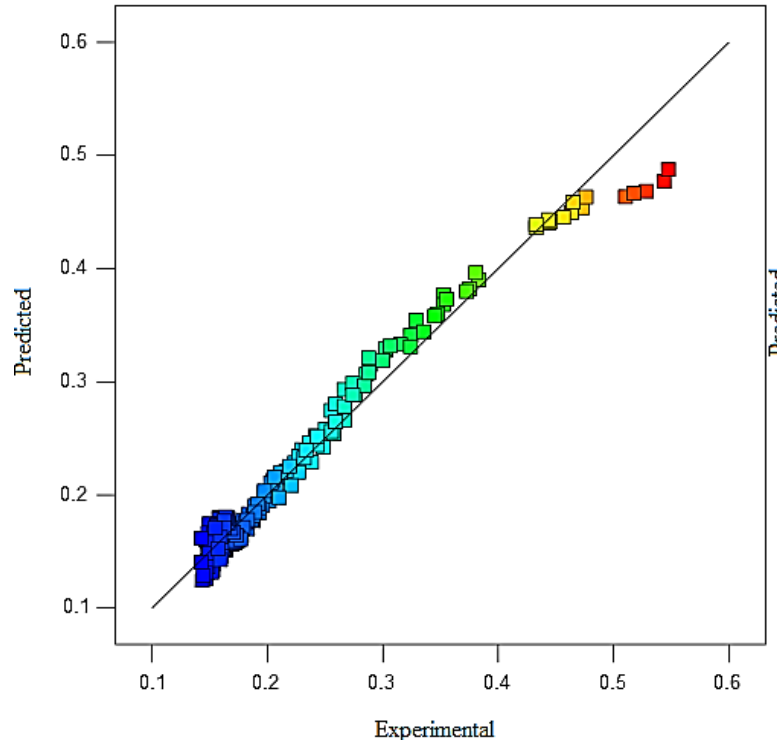

(a)

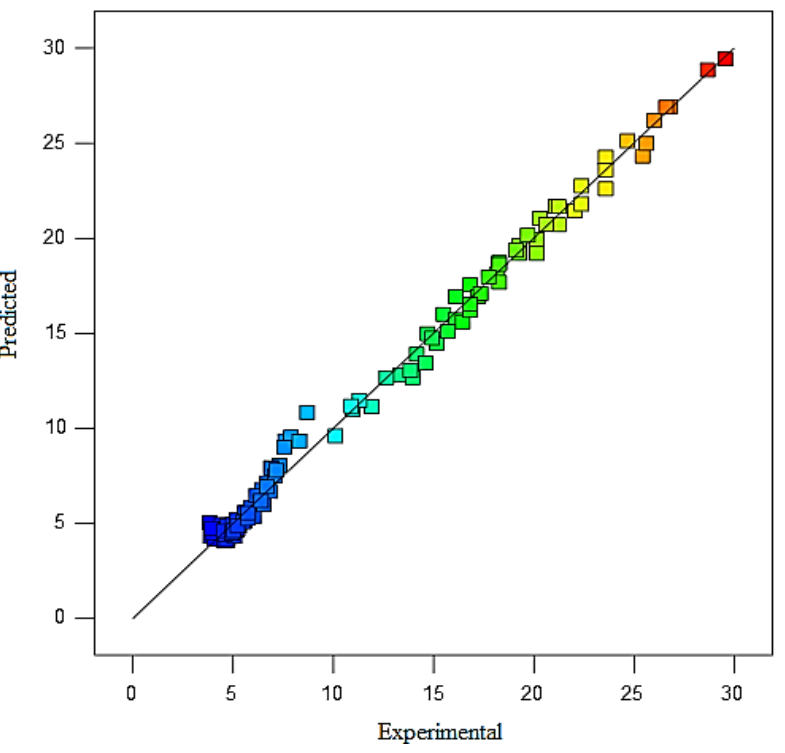

(b)

Figure 5: Comparison of the experimental results and predicted values (a) Friction (b) Nusselt.
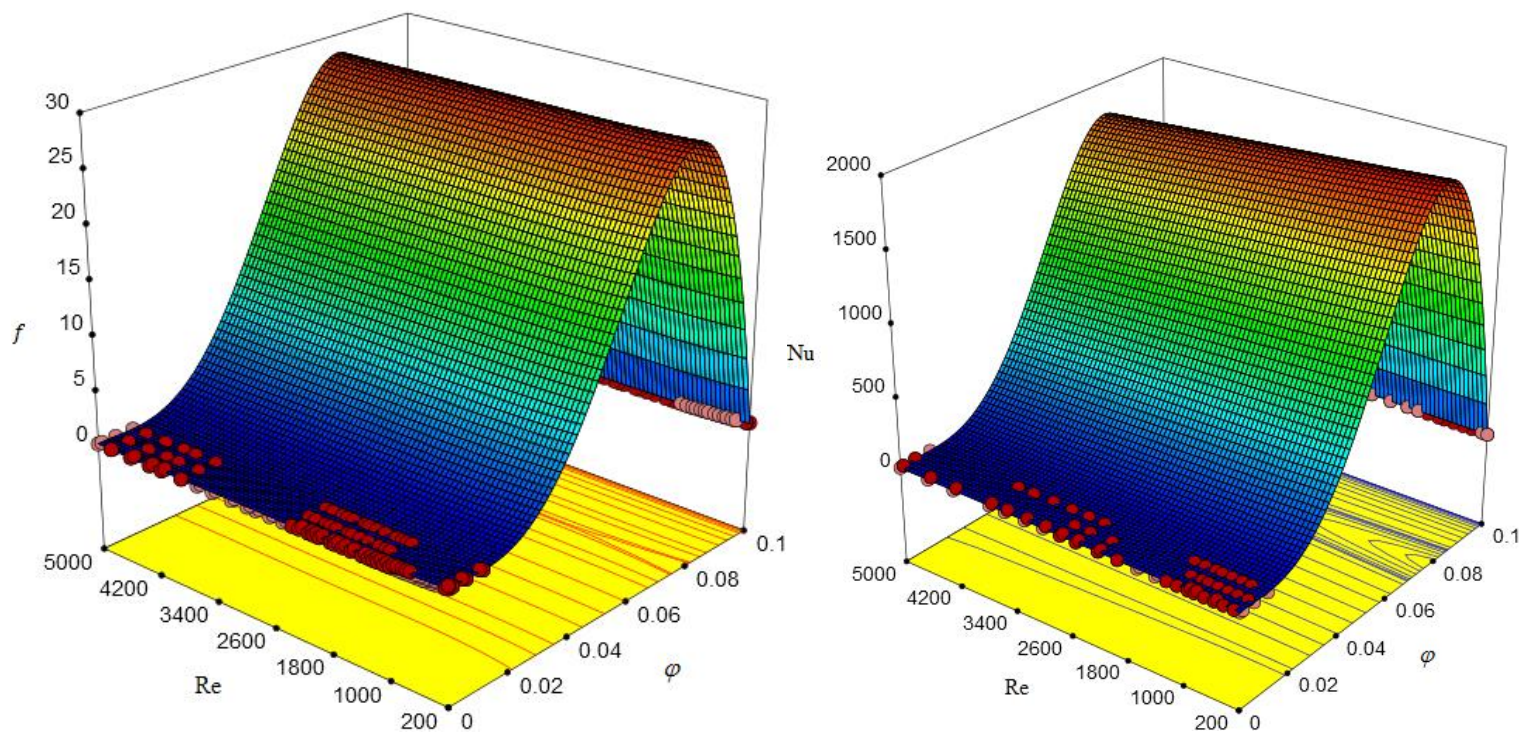

Fig. 6: Three-dimensional response surface graphs of Friction. Fig. 7: Three-dimensional response surface graphs of Nusselt.

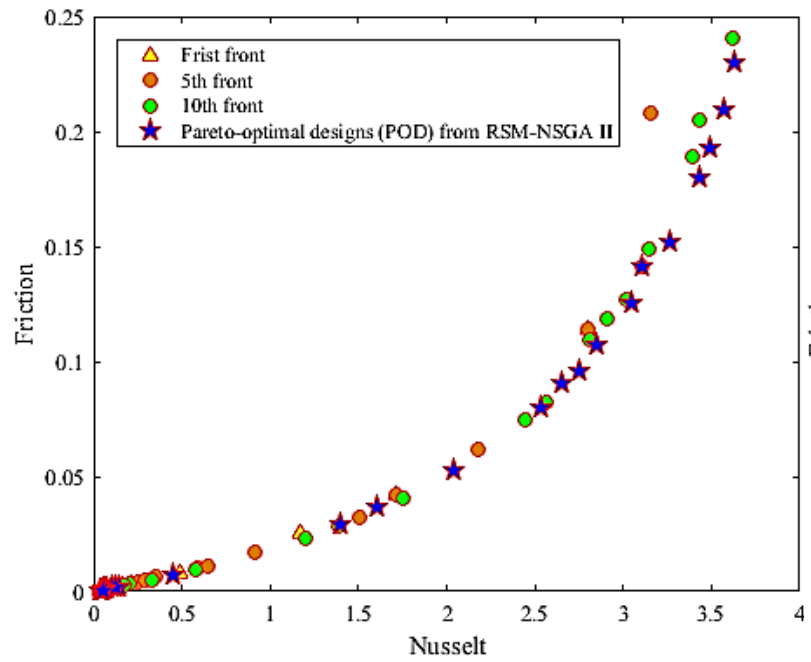

Fig. 8 Multi-objective optimization results by NSGA-II.

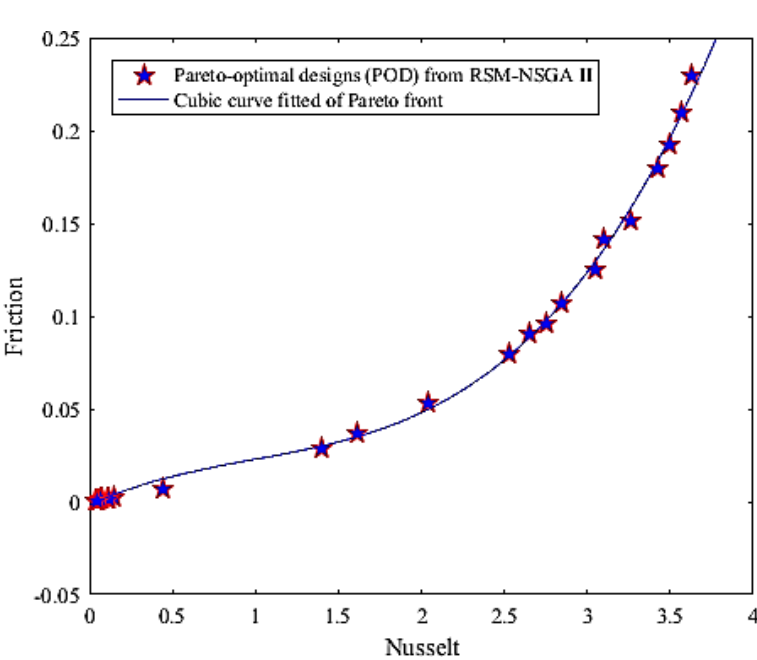

Fig. 9 Pareto optimal front. 
Multi-objective Optimization to Increase Nusselt Number and Reduce Friction Coefficient of Water/Carbon Nanotubes ................

Table 3 shows Analysis of variance (ANOVA) for Friction Tube 1 factor. Table 4 shows Analysis of variance (ANOVA) for Nusselt Tube 1. Figure 10 shows Normal probability plot residuals. (a) Friction (b) Nusselt. Figure 11 shows Comparison of the experimental results and predicted values (a) Friction (b) Nusselt. Figure 12 shows Three-dimensional response surface graphs of Friction. Figure 13 shows Threedimensional response surface graphs of Nusselt. Figure 14 shows Multi-objective optimization results by NSGA-II. Figure 15 shows Pareto optimal front.

Table 3: Analysis of variance (ANOVA) for Friction Tube 1 factor.

\begin{tabular}{|c|c|c|c|c|c|}
\hline Source & Adj SS & Df & Adj MS & $\mathbf{F}$ & $\mathbf{P}$ \\
\hline Model & 2.95 & 14 & 0.21 & 284.80 & $1.10219 \mathrm{E}-114$ \\
\hline$\varphi$ & $1.152 \mathrm{E}-004$ & 1 & $1.152 \mathrm{E}-004$ & 0.16 & 0.6938 \\
\hline $\mathbf{R e}$ & $4.386 \mathrm{E}-004$ & 1 & $4.386 \mathrm{E}-004$ & 0.59 & 0.4427 \\
\hline$\varphi \mathbf{R e}$ & $3.388 \mathrm{E}-004$ & 1 & $3.388 \mathrm{E}-004$ & 0.46 & 0.4998 \\
\hline$\varphi^{2}$ & $1.456 \mathrm{E}-004$ & 1 & $1.456 \mathrm{E}-004$ & 0.20 & 0.6581 \\
\hline $\mathbf{R e}^{2}$ & 0.010 & 1 & 0.010 & 13.88 & 0.0003 \\
\hline$\varphi^{2} \mathbf{R}$ & $2.980 \mathrm{E}-004$ & 1 & $2.980 \mathrm{E}-004$ & 0.40 & 0.5268 \\
\hline$\varphi \mathbf{R e}^{2}$ & $1.493 \mathrm{E}-004$ & 1 & $1.493 \mathrm{E}-004$ & 0.20 & 0.6541 \\
\hline$\varphi^{3}$ & $1.150 \mathrm{E}-004$ & 1 & $1.150 \mathrm{E}-004$ & 0.16 & 0.6942 \\
\hline $\mathbf{R e}^{3}$ & 0.23 & 1 & 0.23 & 308.81 & $6.67316 \mathrm{E}-041$ \\
\hline$\varphi^{2} \mathbf{R e}^{2}$ & $5.926 \mathrm{E}-006$ & 1 & $5.926 \mathrm{E}-006$ & $7.996 \mathrm{E}-003$ & 0.9288 \\
\hline$\varphi^{3} \mathbf{R e}$ & $3.439 \mathrm{E}-004$ & 1 & $3.439 \mathrm{E}-004$ & 0.46 & 0.4966 \\
\hline$\varphi \mathbf{R e}^{3}$ & $4.688 \mathrm{E}-005$ & 1 & $4.688 \mathrm{E}-005$ & 0.063 & 0.8017 \\
\hline$\varphi^{4}$ & $1.206 \mathrm{E}-004$ & 1 & $1.206 \mathrm{E}-004$ & 0.16 & 0.6871 \\
\hline $\operatorname{Re}^{4}$ & 0.22 & 1 & 0.22 & 295.50 & $8.05856 \mathrm{E}-040$ \\
\hline Residual error & 0.13 & 180 & $7.411 \mathrm{E}-004$ & & \\
\hline Total & 3.09 & 194 & & & \\
\hline
\end{tabular}

Table 4: Analysis of variance (ANOVA) for Nusselt Tube 1.

\begin{tabular}{|c|c|c|c|c|c|}
\hline Source & Adj SS & Df & Adj MS & $\mathbf{F}$ & $\mathbf{P}$ \\
\hline Model & 11777.31 & 14 & 841.24 & 939.02 & $2.01451 \mathrm{E}-103$ \\
\hline$\varphi$ & 4.24 & 1 & 4.24 & 4.73 & 0.0318 \\
\hline $\mathbf{R e}$ & 8.08 & 1 & 8.08 & 9.02 & 0.0033 \\
\hline$\varphi \mathbf{R e}$ & 21.49 & 1 & 21.49 & 23.99 & $3.52449 \mathrm{E}-006$ \\
\hline$\varphi^{2}$ & 6.70 & 1 & 6.70 & 7.48 & 0.0073 \\
\hline $\mathbf{R e}^{\mathbf{2}}$ & 13.71 & 1 & 13.71 & 15.31 & 0.0002 \\
\hline$\varphi^{2} \mathbf{R}$ & 15.14 & 1 & 15.14 & 16.90 & $7.82726 \mathrm{E}-005$ \\
\hline$\varphi \mathbf{R e}^{2}$ & 0.062 & 1 & 0.062 & 0.069 & 0.7928 \\
\hline$\varphi^{3}$ & 4.23 & 1 & 4.23 & 4.72 & 0.0320 \\
\hline $\mathbf{R e}^{3}$ & 83.56 & 1 & 83.56 & 93.27 & $3.5952 \mathrm{E}-016$ \\
\hline$\varphi^{2} \mathbf{R e}^{2}$ & 1.50 & 1 & 1.50 & 1.68 & 0.1983 \\
\hline$\varphi^{3} \mathbf{R e}$ & 22.31 & 1 & 22.31 & 24.90 & $2.40538 \mathrm{E}-006$ \\
\hline$\varphi \mathbf{R e}^{\mathbf{3}}$ & 0.61 & 1 & 0.61 & 0.68 & 0.4098 \\
\hline$\varphi^{4}$ & 4.68 & 1 & 4.68 & 5.23 & 0.0242 \\
\hline $\mathbf{R e}^{4}$ & 64.79 & 1 & 64.79 & 72.32 & $1.35666 \mathrm{E}-013$ \\
\hline Residual error & 94.07 & 105 & 0.90 & & \\
\hline Total & 11777.31 & 14 & 841.24 & 939.02 & $2.01451 \mathrm{E}-103$ \\
\hline
\end{tabular}


Petrudi et al., J. Mod. Sim. Mater.; Vol. 3 Issue 1, pp: 1-14, 2020

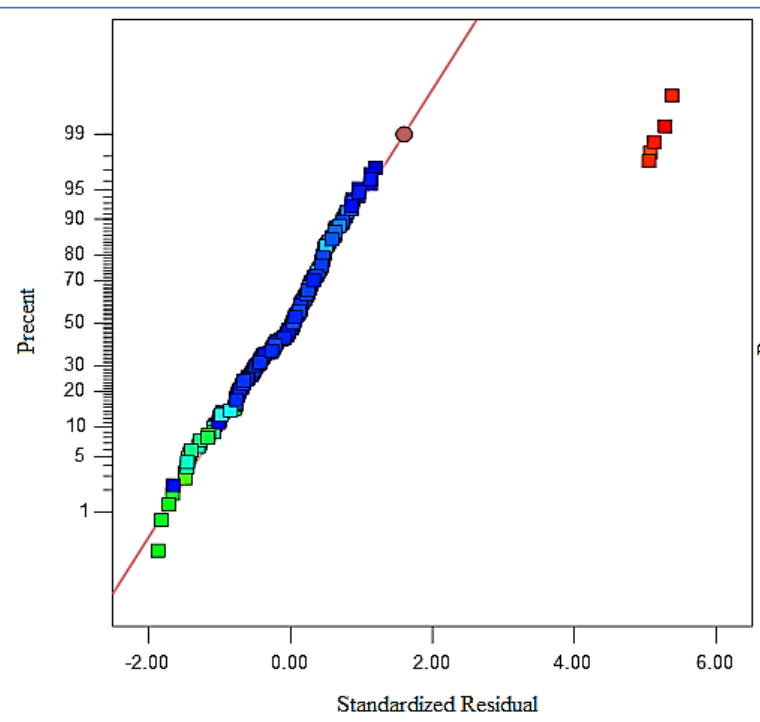

(a)

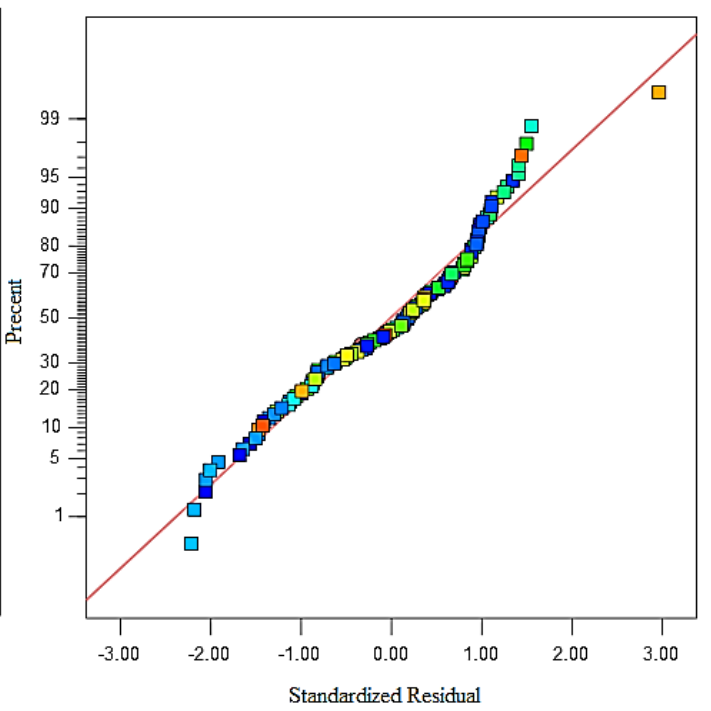

(b)

Fig. 10: Normal probability plot residuals. (a) Friction (b) Nusselt

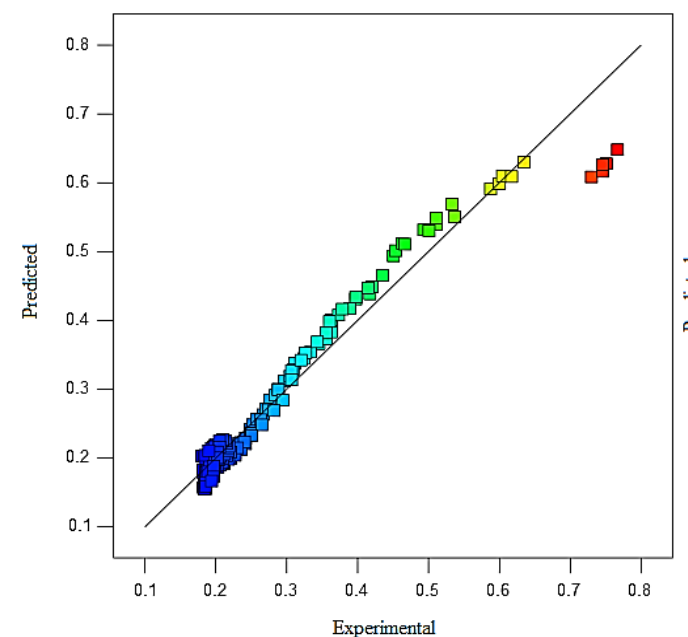

(a)

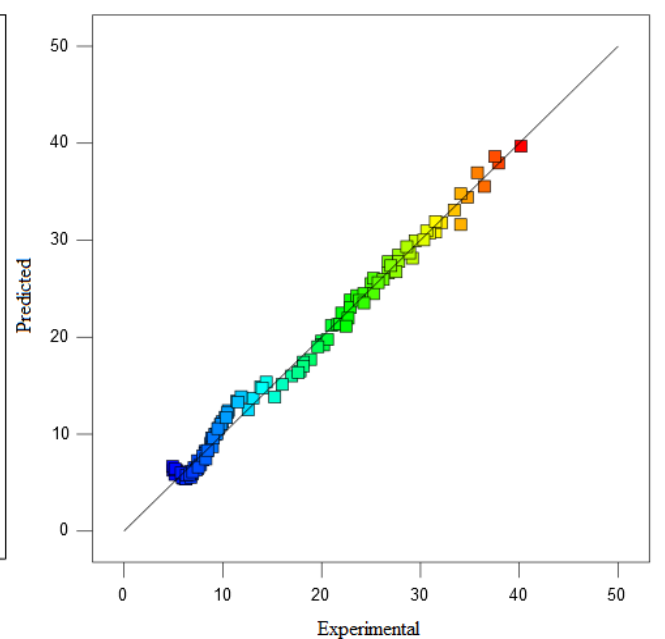

(b)

Fig. 11: Comparison of the experimental results and predicted values (a) Friction (b) Nusselt.
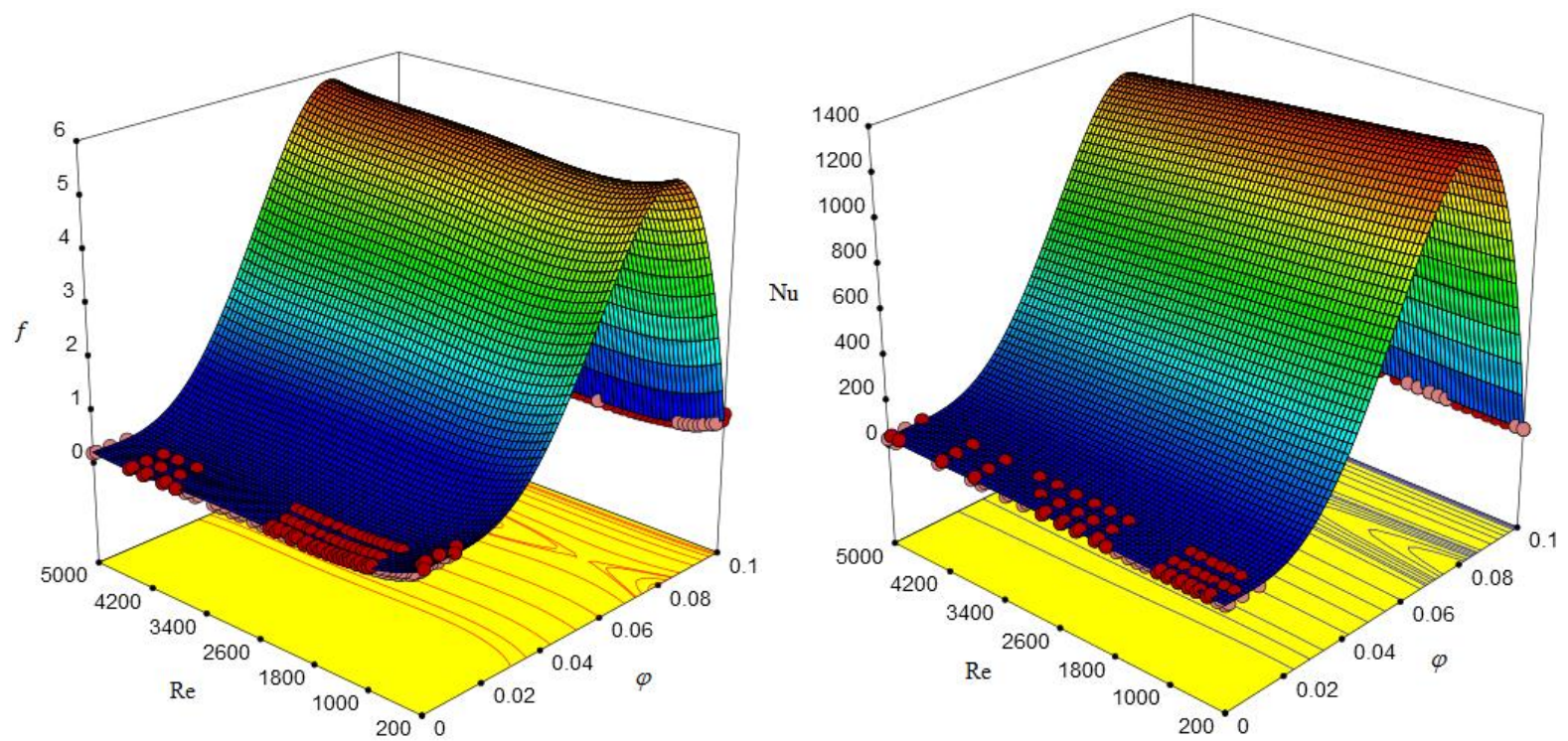

Fig. 12: Three-dimensional response surface graphs of Friction. Fig. 13: Three-dimensional response surface graphs of Nusselt. 
Multi-objective Optimization to Increase Nusselt Number and Reduce Friction Coefficient of Water/Carbon Nanotubes.................

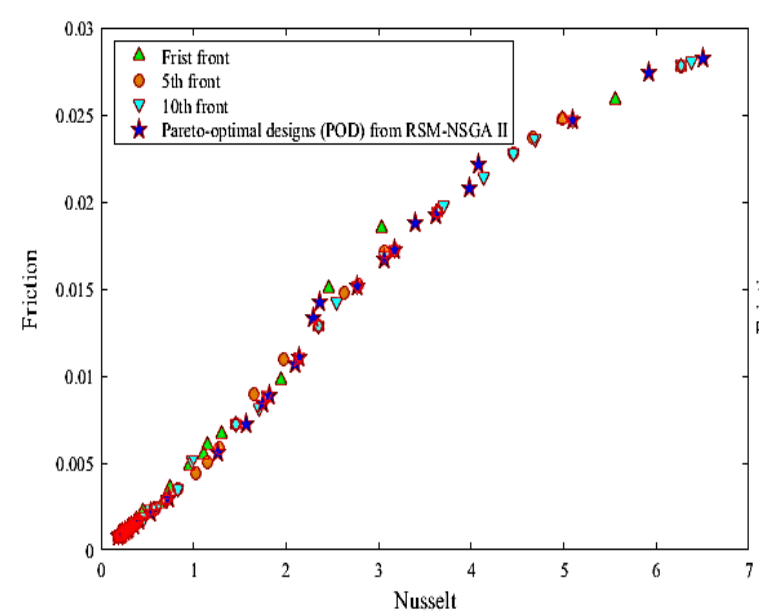

Fig. 14: Multi-objective optimization results by NSGA-II.

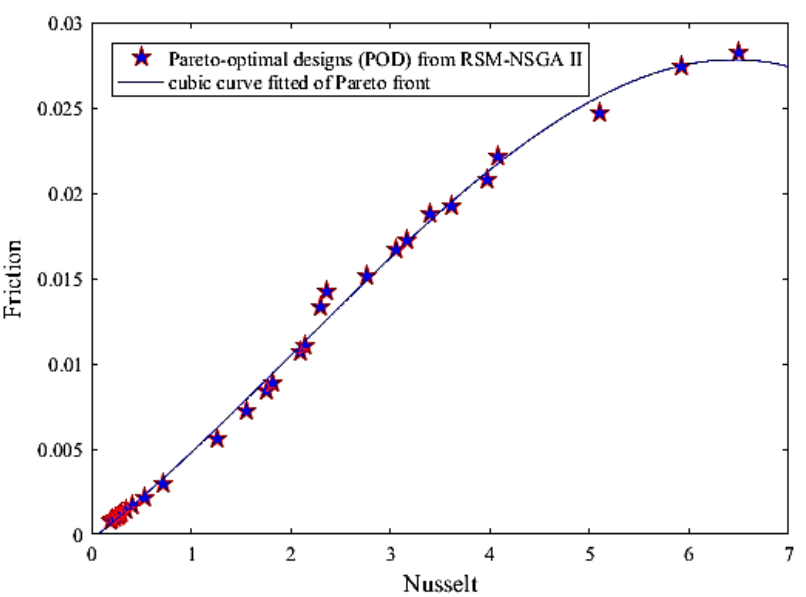

Fig. 15: Pareto optimal front.

Table 5 shows Analysis of variance (ANOVA) for Friction Tube 2 factor. Table 6 shows Analysis of variance (ANOVA) for Nusselt Tube 2. Figure 16 shows Normal probability plot residuals. (a) Friction (b) Nusselt. Figure 17 shows Comparison of the experimental results and predicted values (a) Friction (b) Nusselt. Figure 18 shows Three-dimensional response surface graphs of Friction. Figure 19 shows Threedimensional response surface graphs of Nusselt. Figure 20 shows Multi-objective optimization results by NSGA-II. Figure 21 shows Pareto optimal front.

Table 5: Analysis of variance (ANOVA) for Friction Tube 2 Factor.

\begin{tabular}{|l|c|c|c|c|c|}
\hline Source & Adj SS & Df & Adj MS & F & P \\
\hline Model & 2.95 & 14 & 0.21 & 284.80 & $1.10219 \mathrm{E}-114$ \\
\hline$\varphi$ & $1.152 \mathrm{E}-004$ & 1 & $1.152 \mathrm{E}-004$ & 0.16 & 0.6938 \\
\hline $\mathbf{R e}$ & $4.386 \mathrm{E}-004$ & 1 & $4.386 \mathrm{E}-004$ & 0.59 & 0.4427 \\
\hline$\varphi \mathbf{R e}$ & $3.388 \mathrm{E}-004$ & 1 & $3.388 \mathrm{E}-004$ & 0.46 & 0.4998 \\
\hline$\varphi^{\mathbf{2}}$ & $1.456 \mathrm{E}-004$ & 1 & $1.456 \mathrm{E}-004$ & 0.20 & 0.6581 \\
\hline $\mathbf{R e}^{\mathbf{2}}$ & 0.010 & 1 & 0.010 & 13.88 & 0.0003 \\
\hline$\varphi^{\mathbf{2}} \mathbf{R}$ & $2.980 \mathrm{E}-004$ & 1 & $2.980 \mathrm{E}-004$ & 0.40 & 0.5268 \\
\hline$\varphi \mathbf{R e}^{\mathbf{2}}$ & $1.493 \mathrm{E}-004$ & 1 & $1.493 \mathrm{E}-004$ & 0.20 & 0.6541 \\
\hline$\varphi^{\mathbf{3}}$ & $1.150 \mathrm{E}-004$ & 1 & $1.150 \mathrm{E}-004$ & 0.16 & 0.6942 \\
\hline $\mathbf{R e}^{\mathbf{3}}$ & 0.23 & 1 & 0.23 & 308.81 & $6.67316 \mathrm{E}-041$ \\
\hline$\varphi^{\mathbf{2}} \mathbf{R e}^{\mathbf{2}}$ & $5.926 \mathrm{E}-006$ & 1 & $5.926 \mathrm{E}-006$ & $7.996 \mathrm{E}-$ & 0.9288 \\
\hline$\varphi^{\mathbf{3}} \mathbf{R e}^{2}$ & $3.439 \mathrm{E}-004$ & 1 & $3.439 \mathrm{E}-004$ & 0.46 & 0.4966 \\
\hline $\mathbf{R e}^{\mathbf{3}}$ & $4.688 \mathrm{E}-005$ & 1 & $4.688 \mathrm{E}-005$ & 0.063 & 0.8017 \\
\hline$\varphi^{\mathbf{4}}$ & $1.206 \mathrm{E}-004$ & 1 & $1.206 \mathrm{E}-004$ & 0.16 & 0.6871 \\
\hline $\mathbf{R e}^{\mathbf{4}}$ & 0.22 & 1 & 0.22 & 295.50 & $8.05856 \mathrm{E}-040$ \\
\hline $\mathbf{R e s i d u a l ~ e r r o r ~}^{\mathbf{T}}$ & 0.13 & 180 & $7.411 \mathrm{E}-004$ & & \\
\hline $\mathbf{T o t a l}^{\mathbf{2}}$ & 3.09 & 194 & & & \\
\hline
\end{tabular}


Petrudi et al., J. Mod. Sim. Mater.; Vol. 3 Issue 1, pp: 1-14, 2020

Table 6: Analysis of variance (ANOVA) for Nusselt Tube 2.

\begin{tabular}{|c|c|c|c|c|c|}
\hline Source & Adj SS & Df & Adj MS & $\mathbf{F}$ & $\mathbf{P}$ \\
\hline Model & 11325.51 & 14 & 808.97 & 545.54 & $3.48118 \mathrm{E}-091$ \\
\hline$\varphi$ & 5.43 & 1 & 5.43 & 3.66 & 0.0583 \\
\hline $\operatorname{Re}$ & 5.71 & 1 & 5.71 & 3.85 & 0.0525 \\
\hline$\varphi \mathbf{R e}$ & 16.37 & 1 & 16.37 & 11.04 & 0.0012 \\
\hline$\varphi^{2}$ & 8.16 & 1 & 8.16 & 5.50 & 0.0208 \\
\hline $\mathbf{R e}^{2}$ & 14.26 & 1 & 14.26 & 9.62 & 0.0025 \\
\hline$\varphi^{2} \mathbf{R}$ & 11.83 & 1 & 11.83 & 7.97 & 0.0057 \\
\hline$\varphi \mathbf{R e}^{2}$ & 0.035 & 1 & 0.035 & 0.024 & 0.8776 \\
\hline$\varphi^{3}$ & 5.42 & 1 & 5.42 & 3.66 & 0.0586 \\
\hline $\mathbf{R e}^{3}$ & 75.75 & 1 & 75.75 & 51.08 & $1.21994 \mathrm{E}-010$ \\
\hline$\varphi^{2} \mathbf{R e}^{2}$ & 0.21 & 1 & 0.21 & 0.14 & 0.7079 \\
\hline$\varphi^{3} \mathbf{R e}$ & 17.12 & 1 & 17.12 & 11.54 & 0.0010 \\
\hline$\varphi \mathbf{R e}^{3}$ & 1.01 & 1 & 1.01 & 0.68 & 0.4116 \\
\hline$\varphi^{4}$ & 5.92 & 1 & 5.92 & 4.00 & 0.0482 \\
\hline $\mathbf{R e}^{4}$ & 66.94 & 1 & 66.94 & 45.14 & $9.73105 \mathrm{E}-010$ \\
\hline Residual error & 155.70 & 105 & 1.48 & & \\
\hline Total & 11481.22 & 119 & & & \\
\hline
\end{tabular}

Standard deviation $=1.22$.

Predicted residual error of sum of squares $($ PRESS $)=197.14$.

$\mathrm{R} 2($ Adequate $)=78.479 \% \mathrm{R} 2($ Predicted $)=0.9828 \% \mathrm{R} 2($ Adjusted $)=0.9846 \%$.

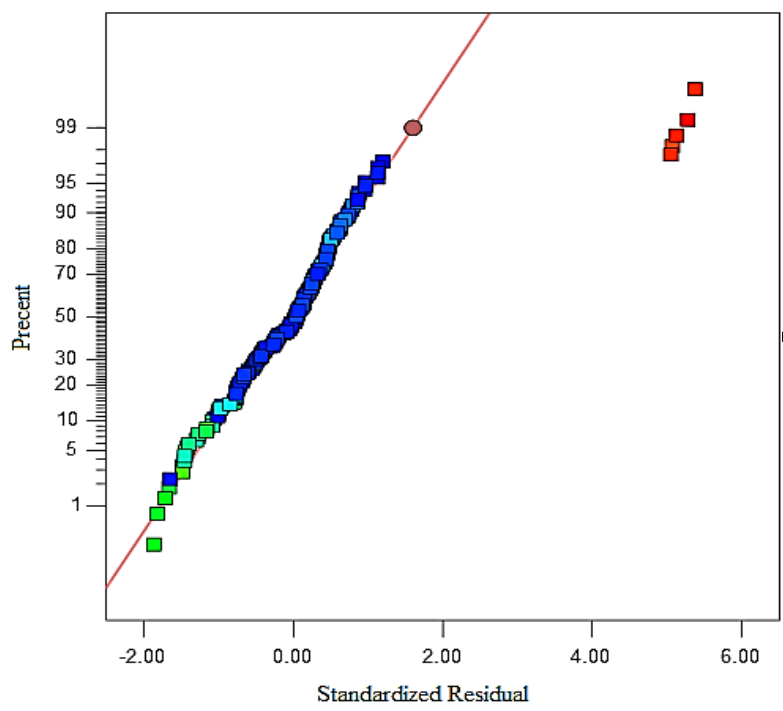

(a)

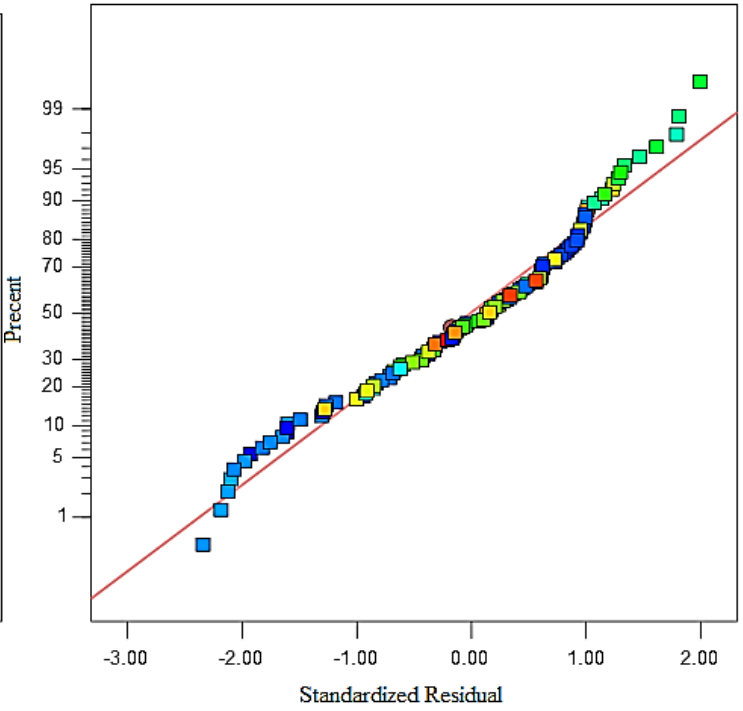

(b)

Fig. 16: Normal probability plot residuals. (a) Friction (b) Nusselt 
Multi-objective Optimization to Increase Nusselt Number and Reduce Friction Coefficient of Water/Carbon Nanotubes................

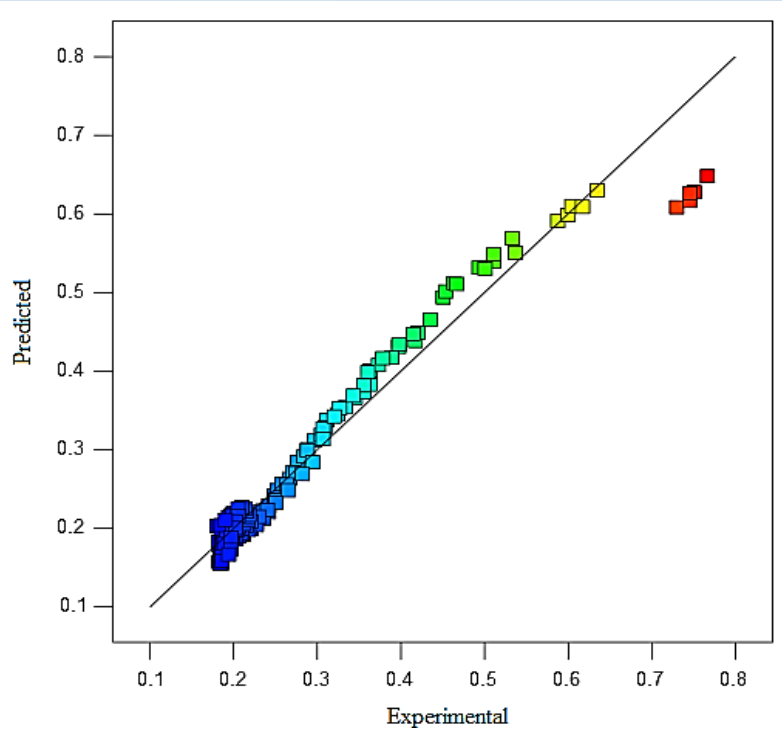

(a)

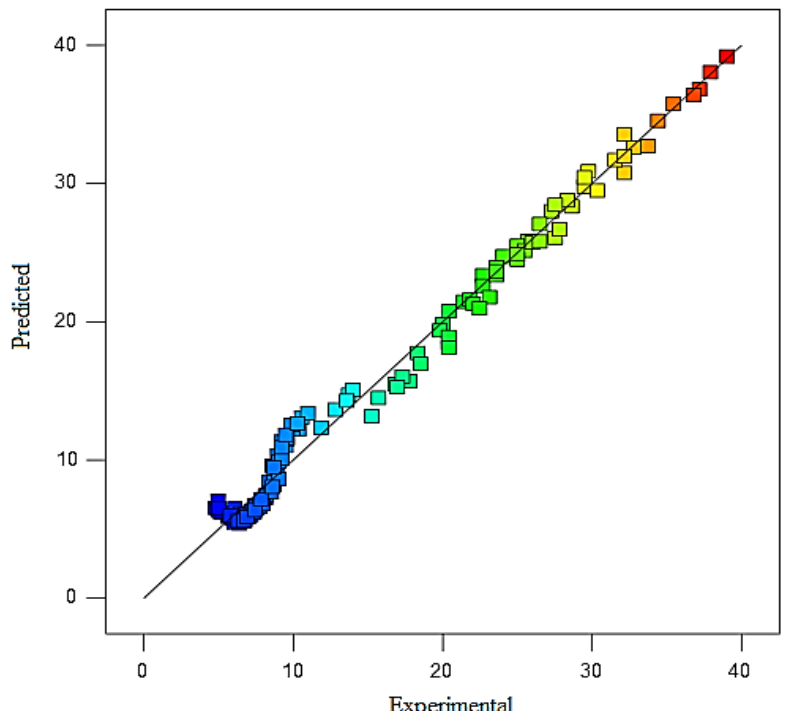

(b)

Fig. 17: Comparison of the experimental results and predicted values (a) Friction (b) Nusselt.
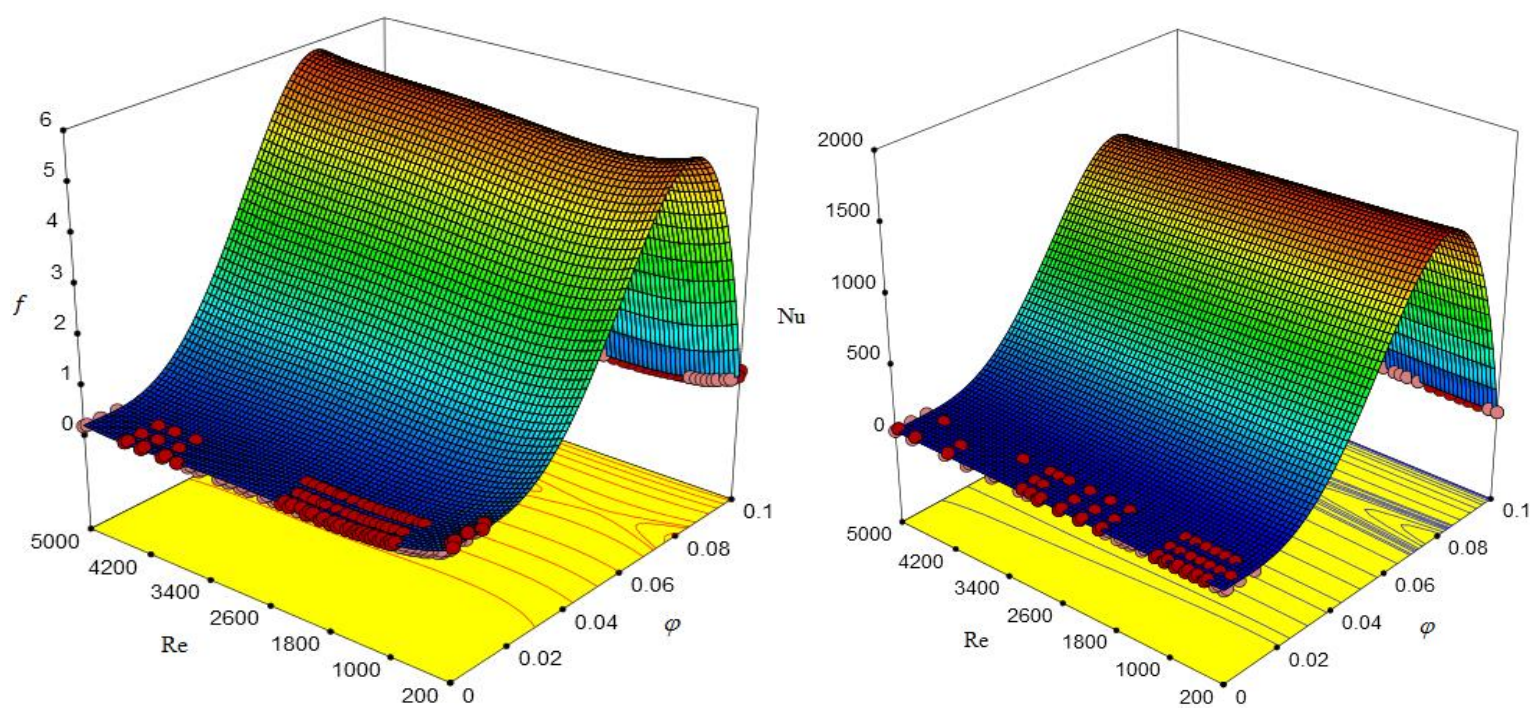

Fig. 18: Three-dimensional response surface graphs of Friction. Fig. 19: Three-dimensional response surface graphs of Nusselt.

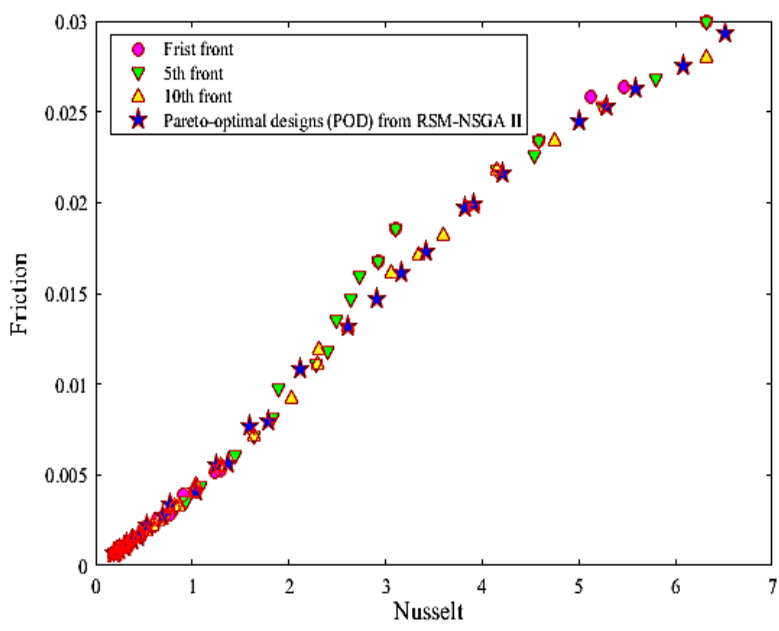

Fig. 20: Multi-objective optimization results by NSGA-II.

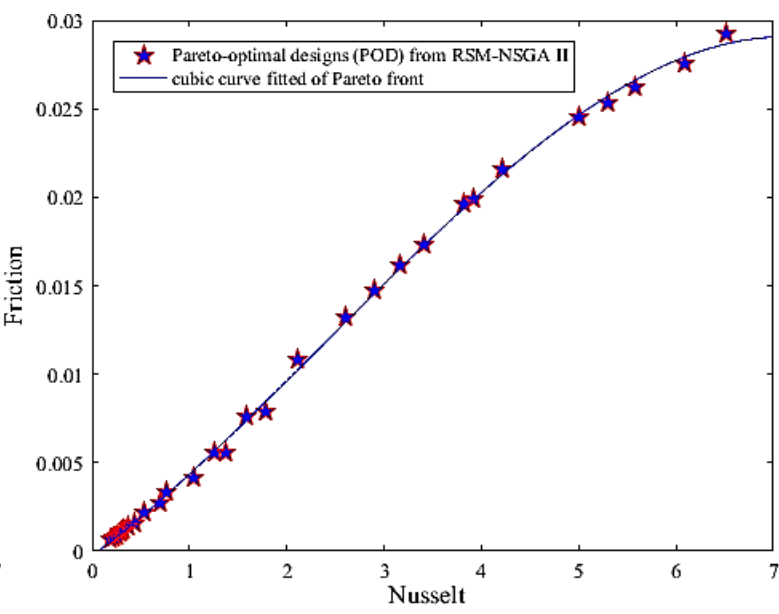

Fig. 21: Pareto optimal front. 


\section{Analysis of variance (ANOVA)}

Variance analysis is a collection of statistical models that examine the mean in groups and dependent functions (such as variance in a group or between groups). In this method, the variance obtained from a random variable is divided into smaller components that are sources of variance, a reliable method for examining the quality of data adaptation to the use of variance analysis. In its simplest form, an ANOVA provides a statistical test that tests the equality of averages of different groups, and therefore, $t$ Student $(t$ test) extends to more than two groups.

\section{Results}

In order to reach the optimal results of the proposed algorithm in several stages and with different values of the number of members of the population, 50 members and the number of iterations have been implemented and presented. in order to compare the optimization process, the results are presented in the first, fifth, tenth and Pareto front. in this paper, the Nusselt number is improved by increasing the volume concentration of nanoparticles as well as Reynolds number. this increase is due to effective thermal conductivity of nanofluid as well as strengthening of nanoparticles. then, by using response surface method (RSM), its data have been extracted. With the help of the achieved curve, the optimum points are Nusselt and the friction coefficient is equal to it.

\section{Conclusion}

The purpose of this study is to optimize the friction coefficient and increase the friction number. this optimization was done by determining the objective functions and experimental data of friction coefficient and Nusselt number of fluid and applying the response surface methodology. in this study, the response surface methodology was determined using the input data of Reynolds number (200 to 5000) and volume fraction (0 to 0.1) to determine the friction coefficient and the Nusselt number. after the variables and objective functions defined in the NSGA II method, multi - objective optimization has been done. and the answers to the friction coefficient and the Nusselt number on the Pareto front were introduced. the results show that the Nusselt number is improved by increasing the volume concentration of nanoparticles as well as Reynolds number. this increase is due to effective thermal conductivity of nanofluid as well as strengthening of nanoparticles. among the obtained results, the points which have the highest number of Nusselt and lowest of friction coefficient have been chosen as the best point.

\section{Competing Interests}

The authors declared that no conflict of interest exist in this publication.

\section{How to Cite this Article:}

A. Moslemi Petrudi, P. Fathi, and M. Rahmani, "Multi-objective Optimization to Increase Nusselt Number and Reduce Friction Coefficient of Water/Carbon Nanotubes via NSGA II using Response Surface Methodology", J. Mod. Sim. Mater., vol. 3, no. 1, pp. 1-14, Mar. 2020. doi: 10.21467/jmsm.3.1.1-14

\section{References}

[1] P. Mohammad Zadeh, T. Sokhansefat, A. B. Kasaeian, F. Kowsary, and A. Akbarzadeh, "Hybrid optimization algorithm for thermal analysis in a solar parabolic trough collector based on nanofluid," Energy, vol. 82, pp. 857-864, 2015.

[2] X. Wang, X. Xu, and S. U. S. Choi, "Thermal Conductivity of Nanoparticle - Fluid Mixture," J. Thermophys. Heat Transf., vol. 13, no. 4, pp. 474-480, Oct. 1999.

[3] A. Esmaeeli, M. Pouladian, A. Monfared, S. R. Mahdavi, and D. Moslemi, "A Genetic Algorithm and Neural Network Hybrid Model to Predict Lung Radiation-Induced Pneumonitis in Breast Radiotherapy (A simulation Study)," Babol-Jbums, vol. 16, no. 1, pp. 77-84, Jan. 2014.

[4] M. Mohammadi, M. Dadvar, and B. Dabir, "TiO2/SiO2 nanofluids as novel inhibitors for the stability of asphaltene particles in crude oil: Mechanistic understanding, screening, modeling, and optimization," J. Mol. Liq., vol. 238, pp. 326-340, 2017.

[5] H. Xie, J. Wang, T. Xi, and Y. Liu, "Thermal Conductivity of Suspensions Containing Nanosized SiC Particles," Int. J. Thermophys., vol. 23, no. 2, pp. 571-580, 2002.

[6] J. Zhou, M. Hatami, D. Song, and D. Jing, "Design of microchannel heat sink with wavy channel and its time-efficient optimization with combined RSM and FVM methods," Int. J. Heat Mass Transf., vol. 103, pp. 715-724, 2016. 
[7] C. Zhang et al., "Numerical and experimental studies on laminar hydrodynamic and thermal characteristics in fractal-like microchannel networks. Part A: Comparisons of two numerical analysis methods on friction factor and Nusselt number," Int. J. Heat Mass Transf., vol. 66, pp. 930-938, 2013.

[8] A. Akbarinia, "Impacts of nanofluid flow on skin friction factor and Nusselt number in curved tubes with constant mass flow," Int. J. Heat Fluid Flow, vol. 29, no. 1, pp. 229-241, 2008.

[9] N. Zhao and Z. Li, "Experiment and Artificial Neural Network Prediction of Thermal Conductivity and Viscosity for AluminaWater Nanofluids," Materials, vol. 10, no. 5. 2017.

[10] K. Milani Shirvan, M. Mamourian, S. Mirzakhanlari, H. F. Öztop, and N. Abu-Hamdeh, "Numerical simulation and sensitivity analysis of effective parameters on heat transfer and homogeneity of A12O3 nanofluid in a channel using DPM and RSM," Adv. Powder Technol., vol. 27, no. 5, pp. 1980-1991, 2016.

[11] S. Iranmanesh, M. Mehrali, E. Sadeghinezhad, B. C. Ang, H. C. Ong, and A. Esmaeilzadeh, "Evaluation of viscosity and thermal conductivity of graphene nanoplatelets nanofluids through a combined experimental-statistical approach using respond surface methodology method,” Int. Commun. Heat Mass Transf., vol. 79, pp. 74-80, 2016.

[12] M. Hemmat Esfe, M. H. Hajmohammad, P. Razi, M. R. H. Ahangar, and A. A. A. Arani, "The optimization of viscosity and thermal conductivity in hybrid nanofluids prepared with magnetic nanocomposite of nanodiamond cobalt-oxide (ND-Co3O4) using NSGA-II and RSM,” Int. Commun. Heat Mass Transf., vol. 79, pp. 128-134, 2016.

[13] S.-M. Huang, C.-H. Kuo, C.-A. Chen, Y.-C. Liu, and C.-J. Shieh, "RSM and ANN modeling-based optimization approach for the development of ultrasound-assisted liposome encapsulation of piceid," Ultrason. Sonochem., vol. 36, pp. 112-122, 2017.

[14] P. E. Ohale, C. F. Uzoh, and O. D. Onukwuli, "Optimal factor evaluation for the dissolution of alumina from Azaraegbelu clay in acid solution using RSM and ANN comparative analysis," South African J. Chem. Eng., vol. 24, pp. 43-54, 2017.

[15] M. R. Sabour and A. Amiri, "Comparative study of ANN and RSM for simultaneous optimization of multiple targets in Fenton treatment of landfill leachate,” Waste Manag., vol. 65, pp. 54-62, 2017.

[16] H. E. Patel, S. K. Das, T. Sundararajan, A. Sreekumaran Nair, B. George, and T. Pradeep, "Thermal conductivities of naked and monolayer protected metal nanoparticle based nanofluids: Manifestation of anomalous enhancement and chemical effects," Appl. Phys. Lett., vol. 83, no. 14, pp. 2931-2933, Sep. 2003.

[17] K. Milani Shirvan, M. Mamourian, S. Mirzakhanlari, and R. Ellahi, "Numerical investigation of heat exchanger effectiveness in a double pipe heat exchanger filled with nanofluid: A sensitivity analysis by response surface methodology," Powder Technol., vol. 313, pp. 99-111, 2017.

[18] A. Kumar et al., "Correlation development for Nusselt number and friction factor of a multiple type V-pattern dimpled obstacles solar air passage," Renew. Energy, vol. 109, pp. 461-479, 2017.

[19] T. Y. Lin and C. H. Tseng, “Optimum design for artificial neural networks: an example in a bicycle derailleur system,” Eng. Appl. Artif. Intell., vol. 13, no. 1, pp. 3-14, 2000.

[20] M. Hatami, "Nanoparticles migration around the heated cylinder during the RSM optimization of a wavy-wall enclosure," Adv. Powder Technol., vol. 28, no. 3, pp. 890-899, 2017.

[21] M. Hatami, M. J. Z. Ganji, I. Sohrabiasl, and D. Jing, "Optimization of the fuel rod's arrangement cooled by turbulent nanofluids flow in pressurized water reactor (PWR)," Chinese J. Chem. Eng., vol. 25, no. 6, pp. 722-731, 2017.

[22] T. B. Gorji and A. A. Ranjbar, "Thermal and exergy optimization of a nanofluid-based direct absorption solar collector," Renew. Energy, vol. 106, pp. 274-287, 2017.

\section{Publish your research article in AIJR journals- \\ - Online Submission and Tracking \\ - Peer-Reviewed \\ - Rapid decision \\ - Immediate Publication after acceptance \\ - Articles freely available online \\ - Retain full copyright of your article. \\ Submit your article at journals.aijr.in}

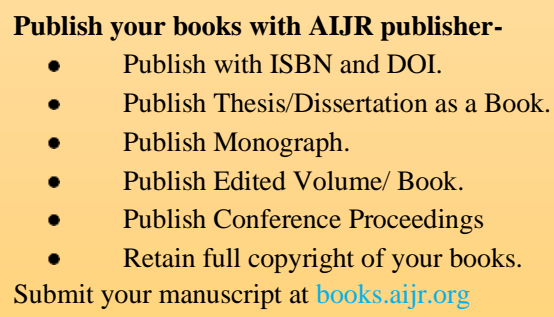

Publish your books with AIJR publisher-

- $\quad$ Publish with ISBN and DOI

- $\quad$ Publish Thesis/Dissertation as a Book.

- Publish Monograph

- Publish Edited Volume/ Book

- Retain full copyright of your books.

Submit your manuscript at books.aijr.org 